Research Article

\title{
Dynamic Stiffness and Damping Characteristics of a Shaft Damping Ring: A Combined Hyperelastic and Viscoelastic Constitutive Model
}

\author{
Miaomiao Li (D), ${ }^{1}$ Jian Chen, ${ }^{1}$ Rupeng Zhu, ${ }^{1}$ Cheng Duan, ${ }^{2}$ Shuai Wang, ${ }^{2}$ and Xiong Lu ${ }^{2}$ \\ ${ }^{1}$ National Key Laboratory of Science and Technology on Helicopter Transmission, \\ Nanjing University of Aeronautics and Astronautics, Nanjing 210016, China \\ ${ }^{2}$ AECC Hunan Aviation Powerplant Research Institute, Zhuzhou 412000, China
}

Correspondence should be addressed to Miaomiao Li; limiaomiao@nuaa.edu.cn

Received 16 June 2020; Revised 16 September 2020; Accepted 23 September 2020; Published 5 October 2020

Academic Editor: Marco Cocconcelli

Copyright (C) 2020 Miaomiao Li et al. This is an open access article distributed under the Creative Commons Attribution License, which permits unrestricted use, distribution, and reproduction in any medium, provided the original work is properly cited.

At higher velocities, the helicopter tail transmission system encounters notable difficulties due to excessive bending vibrations. The shaft damping ring installed on the shaft system was shown to effectively suppress the shaft system vibrations. In this paper, the dynamic stiffness and damping characteristics of polyurethane shaft damping rings were studied using hyperelastic and viscoelastic constitutive models. The constitutive model and the damping ring material parameters were determined using uniaxial tensile and double-shear frequency scanning tests. Based on the test results, the dynamic damping ring characteristics were simulated and verified by dynamic stiffness tests; the influence of structural parameters and operating conditions on the dynamic stiffness and damping characteristics of the damping ring were obtained. The results provide a theoretical basis for the design of shaft systems with reduced sensitivity to vibrations.

\section{Introduction}

The tail drive system is an essential subsystem of helicopter drive, characterized by a long drive chain, multiple elastic supports, and high speed [1]. When the tail drive shaft system is running at high speed, the vibrations become a prominent problem. In the supercritical tail drive systems, the vibration amplitude sharply increases when passing the critical speed due to resonance. If the vibration is not properly addressed, the system might become overloaded, causing shaft movement instability. This problem is mitigated by installing a shaft damping ring between the outer shaft bearing system ring and the bearing housing bore. This operation effectively reduces the influence of the shaft system bending vibrations on the helicopter body and reduces the transmission of vibrations caused by other sources to the shaft system.

In the field of aviation, the transmission shaft vibrations are mainly reduced through elastic supports [2], squeeze film dampers [3], dry-friction dampers [4], and viscoelastic damping rings [5], among others. Polyurethane elastomer is often used as a sealing element of the shaft damping ring, having the advantages of both elastic supports and dampers. It has a longer useful life than a dry-friction damper. Polyurethane elastomer is a novel rubber damping material, which has both high tensile strength and resilience in combination with high hardness. Its breaking strength and bearing capacity are much higher when compared to traditional rubber, with good damping properties and exceptional oil and oxygen resistances.

The application of the viscoelastic damping ring in the tail drive shaft system can be traced back to the S-64 "Air Crane" helicopter first flown by Sikorsky company in 1962, in which similar damping devices were installed in the horizontal drive shaft [6]. Hill summarized the analytical method to find the static stiffness of the rubber damping ring. The method based on a nonlinear shape coefficient was proven to be the most representative [7]. Sheng et al. 
determined the constitutive model parameters for rubber by carrying out uniaxial tensile experiments. The experimental data was then implemented into the finite element software (ABAQUS) to simulate the static stiffness; and the static stiffness of the rubber block was calculated. The finite element method accuracy is verified by comparison of simulation and experimental results [8]. Lee et al. obtained the rubber ring hysteresis loop through the finite element method and then combined it with the empirical formula to obtain the dynamic stiffness of the rubber. The method was verified experimentally [9]. Liu et al. conducted a simulation analysis on the polyurethane vibration isolator, obtaining its static stiffness, dynamic stiffness, and natural frequency. Similar to other studies, the results of the finite element simulation were experimentally verified [10]. Li et al. both numerically and experimentally simulated rubber shock absorbers of various cross-sectional shapes. The boundary conditions were varied to obtain the radial stiffness law for different cross-sectional shapes and boundary conditions [11]. Xie et al. conducted experiments on both the dynamic and static performance of polyurethane and natural rubber vibration isolators. The experimental results have shown that polyurethane vibration isolator has a lower natural frequency and stronger load-bearing capacity compared to natural materials [12]. Yang and Wang designed the polyurethane vibration isolator and verified its vibration isolation performance through finite element and MATLAB simulation [13]. Huang et al. predicted the rubber damping ring stiffness by using FEM; after establishing the material model with frequency variation, the unit harmonic displacement load was analyzed while also considering the predeformation. The stiffness was calculated using the frequency response analysis and according to the corresponding constraint conditions. The presented method is applicable to various kinds of damping ring structures; however, the rubber material properties characterized by the Yeoh model are not accurate enough for all constitutive material models [14]. Liu et al. studied the diesel engine polyurethane vibration isolators and obtained the displacement of the vibration isolator reference point under the vertical and radial rated load. The static and dynamic stiffness were also obtained. However, it should be noted that, in the simulation analysis, the polyurethane material was defined by the elastic modulus and Poisson's ratio, therefore, lacking the constitutive model establishment. Additionally, the material setting was too rough [15].

Previously published studies on the rubber damping ring stiffness and damping characteristics have rarely focused on the reduction of shaft vibrations, particularly on the damping ring type under the radial load. The existing simulation analyses frequently failed to consider the constitutive model of the material and the necessary tests. Moreover, both the factors affecting the dynamic stiffness and damping characteristics were often unclear. On the other hand, the dynamic stiffness and damping characteristics directly impact the vibration reduction control of the shaft damping ring, thus having a beneficial effect on the helicopter tail drive shaft. Therefore, understanding its characteristics is an important basis when designing the tail drive system. This paper establishes an accurate polyurethane material constitutive model through the uniaxial tension and double-shear frequency scanning test. Following the test, the numerical simulation and experimental research on the dynamic stiffness and damping characteristics of the shaft damping ring were carried out, ensuring the reliability of the results. The research results provided a theoretical reference for the analysis and design of shaft damping rings.

\section{The Polyurethane Material Constitutive Model}

The dynamic characteristic simulation of the shaft damping ring is based on the polyurethane material constitutive model; therefore, an accurate model is necessary to ensure both the reliability and accuracy of results. Due to the rubber material viscoelasticity, its constitutive relation is nonlinear, making it impossible to accurately describe its mechanical properties using Young's modulus and Poisson's ratio. At the same time, the processing technology and raw material composition during rubber production have a significant influence on the constitutive model, significantly affecting the mechanical properties of rubber materials. Therefore, it is necessary to establish the constitutive model by formulating the material parameters through the basic rubber test.

\subsection{Hyperelastic Constitutive Model}

2.1.1. Uniaxial Tensile Test of Polyurethane Material. Generally, the rubber material hyperelasticity parameters can be obtained by using the uniaxial tensile test. In this paper, the authors used the GABO EPLEXOR dynamic thermomechanical analyzer to carry out the uniaxial tensile test on polyurethane rubber specimens (see Figure 1). The Mullins effect of polyurethane materials should also be noted. When the rubber undergoes the loading-unloadingreloading cycle, the unloading and reloading stresses are lower than the loading stress. When reloading, the stressstrain curve first follows the unloading path with the increase in strain. With the further increase in strain, the stress-strain curve coincides with the main curve. For this reason, to eliminate the Mullins effect, a uniaxial tensile test was carried out three times with the preloading [16].

The hardness of the shaft damping ring studied in this paper is shore $70 \mathrm{~A}$, and the polyurethane piece used in the constitutive model test is made of the same material batch. The stretching fixture was fixed to the main box of the dynamic thermomechanical analyzer using a buckle, thus clamping the polyurethane piece. The static stretching of the polyurethane piece is shown in Figure 2. At room temperature of $25^{\circ} \mathrm{C}$, the loading speed was controlled to $60 \mathrm{~mm} / \mathrm{min}$, and the Mullins effect was eliminated by three cycles of prestretching. The stress-strain data of the fourth polyurethane piece was recorded, and the stress-strain curve of polyurethane rubber material in the tensile state was obtained (see Figure 3).

Figure 3 shows that tensile stress exhibits typical nonlinear characteristics as the strain increases. In other words, when the tensile strain is low, the increase rate of corresponding 


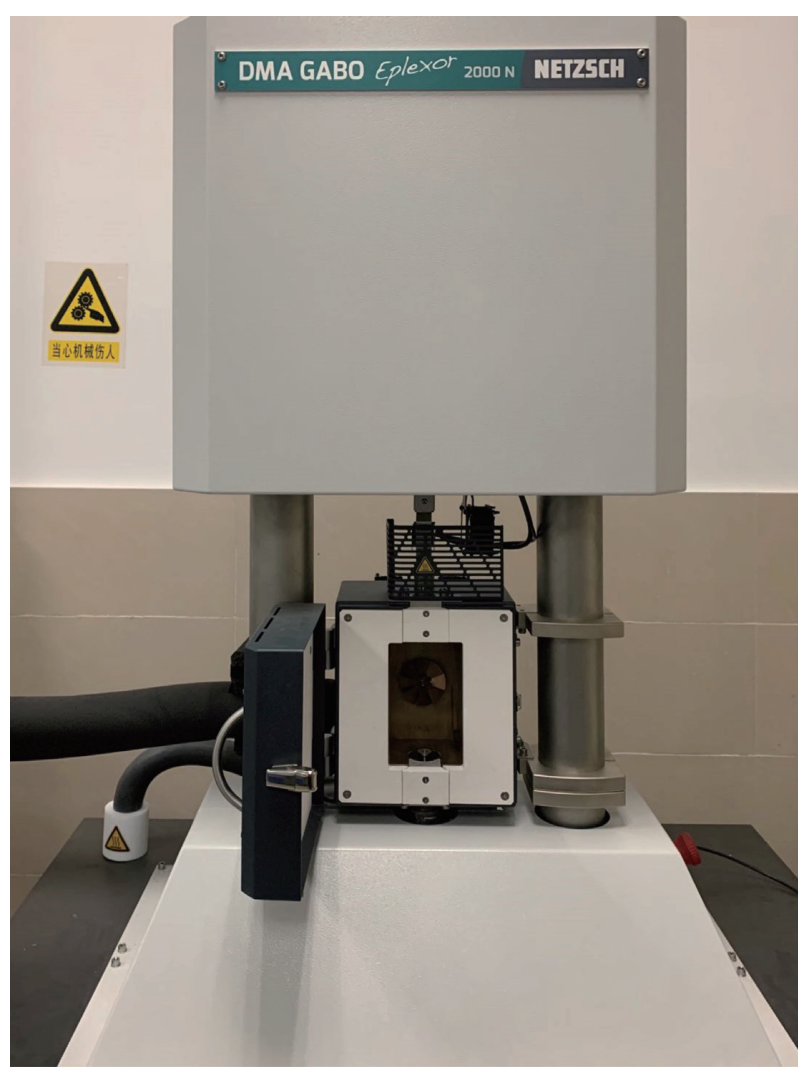

FIgURE 1: GABO EPLEXOR (dynamic thermophysical analyzer).

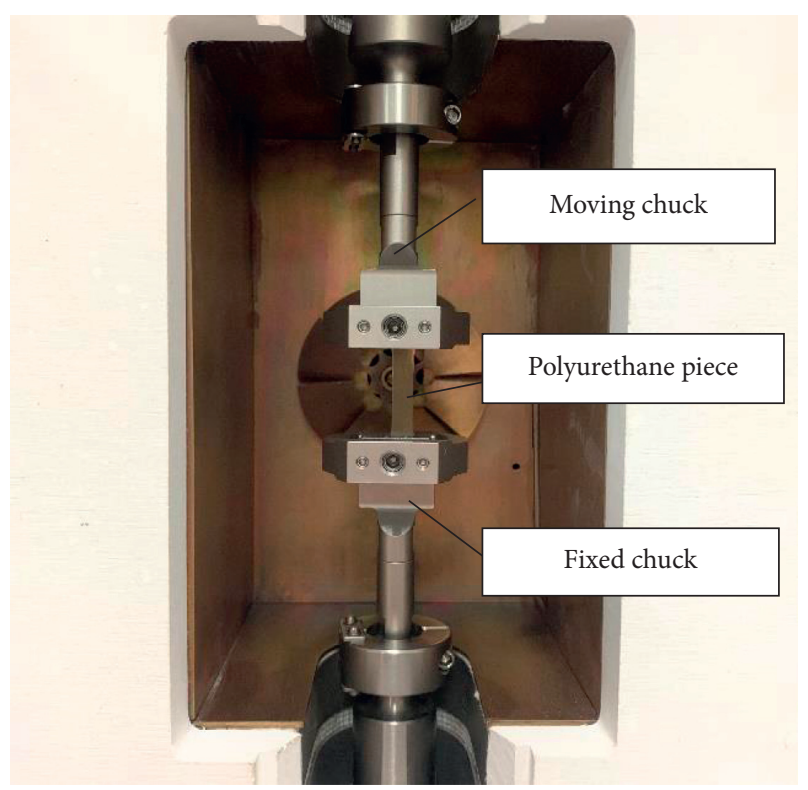

FIgURE 2: Static tension of the polyurethane piece.

stress gradually decreases. In the opposite case, when the increase rate of corresponding stress gradually increases with the increase of strain, there is a steep rise trend.

2.1.2. Parameters Determination of the Hyperelastic Constitutive Model. The hyperelastic constitutive models are divided into two categories. The first is based on the

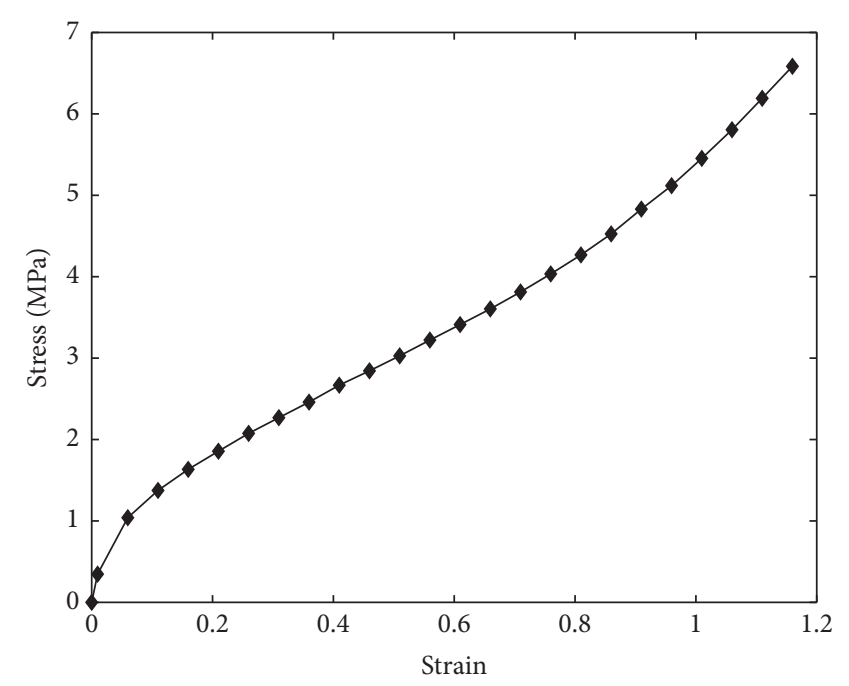

FIGURE 3: Uniaxial tensile stress-strain of polyurethane rubber piece.

phenomenological theory of continuum, such as the Mooney-Rivlin model, Yeoh model, and Neo-Hookean model, among others. The second category includes models based on thermodynamic statistical methods, such as the Arruda-Boyce model. These two theories can be expressed by the method of strain energy density function [17], while the strain energy density function $W$ can be used to represent the functions of the three invariants $I_{1}, I_{2}$, and $I_{3}$ of the deformation tensor:

$$
W=W\left(I_{1}, I_{2}, I_{3}\right)
$$

Based on the rubber material incompressibility, namely, $I_{3} \equiv 1$, the isotropic incompressible material strain energy density function $W$ can be expressed using the Rivlin model:

$$
W=\sum_{i=0, j=0}^{N} C_{i j}\left(I_{1}-3\right)^{i}\left(I_{2}-3\right)^{j} \quad(i+j \geq 1),
$$

where $C_{i j}$ is the experimentally determined material constant and $N$ is typically less than 5 . Rivlin model is the fundamental constitutive model of rubber. Based on (2), the strain energy density function model of hyperelastic materials can be obtained.

(1). Mooney-Rivlin Model. The Mooney-Rivlin model is a classical model commonly used in engineering as it can simulate the mechanical behavior of practically all rubber materials. As such, it is suitable for finite element analysis. The model can accurately describe the small-to-moderate rubber material strain; the mechanical properties of rubber materials with large strain are poorly described.

Based on the Rivlin model, $N=1$ is assumed, aiming to expand the first two terms, that is, the Mooney-Rivlin model. The strain energy density function is expressed as

$$
W=C_{10}\left(I_{1}-3\right)+C_{01}\left(I_{2}-3\right) \text {. }
$$


(2). Yeoh Model. When compared to the Mooney-Rivlin models, Yeoh models for elastic rubber material properties have a more accurate description, broader scope, and better describe the deformation at different ranges. As such, they are especially suitable for rubber materials under large deformation, providing a high level of precision. They also describe a shear modulus model more accurately. Additionally, in the small deformation range, the Yeoh fitting test data have a small deviation; however, the absolute error is minimal.

Yeoh model is a cubic strain energy function in the form of $\left(I_{1}-3\right)$, which is a special form of polynomial model reduction. When $j \neq 0$, all $C_{i j}$ are equal to 0 , and $N=3$. The Yeoh model can be expressed as

$$
W=C_{10}\left(I_{1}-3\right)+C_{20}\left(I_{1}-3\right)^{2}+C_{30}\left(I_{1}-3\right)^{3} .
$$

In the previous equation, $\left(C_{10}\right),\left(C_{20}\right)$, and $C_{30}$ are the Yeoh constitutive model parameters.

(3). Neo-Hookean Model. The Neo-Hookean model is a constant shear model, which can only be used to predict the mechanical behavior of uniaxial tensile rubber with strain ranges between $30 \%$ and $40 \%$ and pure shear rubber with strain ranges between $80 \%$ and $90 \%$. The model is the simplest form of elastic body strain energy function and can be expressed as follows:

$$
W=C_{10}\left(I_{1}-3\right),
$$

where $C_{10}=0.5 \mu \mathrm{G}$ and $\mu \mathrm{G}$ is the material shear modulus.

(4). Arruda-Boyce Model. The Arruda-Boyce model, also known as the eight-chain model, is a non-Gaussian chain network model based on the statistical thermodynamics method. The strain energy function is

$$
W=\mu \sum_{i=1}^{N} \frac{C_{i}}{\lambda_{m}^{2 i-2}}\left(I_{1}^{i}-3^{i}\right)+\frac{1}{D}\left(\frac{J_{\mathrm{el}}^{2}-1}{2}-\ln \ln J_{\mathrm{el}}\right),
$$

where $\mu$ and $\lambda_{m}$ are test data material constants; $J_{\mathrm{el}}$ is the elastic volume ratio; and $D$ is the compression characteristic volume modulus. In general, if $N$ is equal to $5, C_{1}$ to $C_{5}$ are constants; their values are obtained by the thermodynamic statistical method.

According to the uniaxial tensile test data of polyurethane samples, the Mooney-Rivlin, Neo-Hookean, Yeoh, and Arruda Boyce models are fitted. The hyperelastic constitutive models curves are shown in Figure 4, while the parameters determined by the fitting are shown in Table 1.

As seen in Figure 4, the Mooney-Rivlin model is in line with the experimental data in the small and medium deformation range, while deviating in the large deformation range. Yeoh model shows a good fitting effect in the whole uniaxial tensile deformation range of polyurethane rubber specimens, primarily in the small and large deformation ranges. Furthermore, the Yeoh model fitting coefficients $C_{10}$ and $C_{20}$ are of the same order of magnitude, while $C_{30}$ is one order of magnitude lower (as shown in Table 1); additionally, $C_{20}$ typically has a negative value. Since $C_{20}$ is negative, the

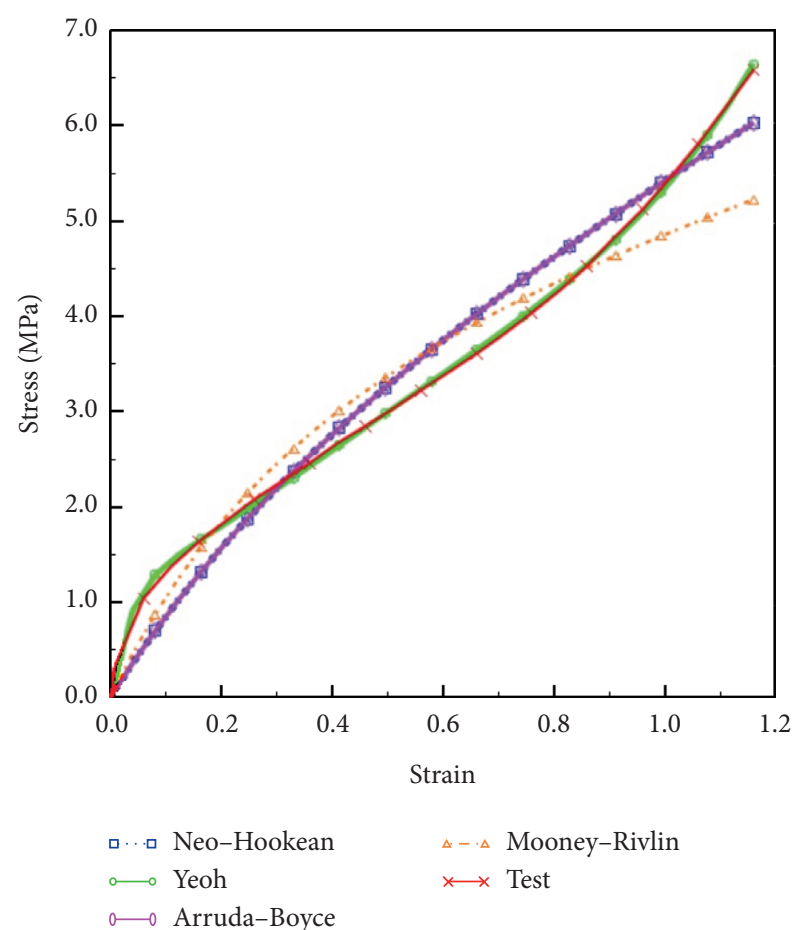

FIgURE 4: Fitting curves of hyperelastic models in the uniaxial tensile test.

rubber material behavior in the low (Yeoh model fitting curve expression "soft") and high strain ranges differs as a result of $C_{30}$ and $C_{10}, C_{20}$ orders of magnitude. The fitting curve reflects the "alarming" phenomenon very accurately, ensuring the relatively good fitting effect in the medium deformation stages. Finally, in a small deformation stage, there is a minimal error. When considering the remaining two models, the Neo-Hookean, and Arruda-Boyce model, the fitting curves are practically coinciding.

Based on the previously presented results, the authors have selected the third-order Yeoh model as the hyperelastic constitutive model of shore $70 \mathrm{~A}$ polyurethane rubber material.

\subsection{Viscoelastic Constitutive Model}

2.2.1. Double-Shear Sweep Test of Polyurethane Material. The rubber material viscoelasticity is characterized by stress relaxation and creep in the time domain and by the dynamic rubber properties as the frequency varies in the frequency domain. The dynamic thermomechanical analyzer was used to measure the relationship between energy storage modulus and loss modulus when the material is periodically subjected to stress by using frequency. In this paper, the frequency scanning test under double-shear was carried out on the shore $70 \mathrm{~A}$ polyurethane specimen.

The polyurethane pieces of double-shear frequency scanning and uniaxial tensile test were made of the same material. The test was then started simultaneously, with the polyurethane pieces being a $2 \mathrm{~mm}$ thick sheet cylinder. The 
TABLE 1: Fitting parameters of each hyperelastic constitutive model for shore $70 \mathrm{~A}$.

\begin{tabular}{lc}
\hline Hyperelastic constitutive model & Fit parameter value \\
\hline Mooney-Rivilin model & $C_{10}=1.2969 \mathrm{E} 6, C_{01}=7.3557 \mathrm{E} 5$ \\
Neo-Hookean model & $C_{10}=3.0994 \mathrm{E} 6$ \\
Third-order Yeoh model & $C_{10}=1.9597 \mathrm{E} 6, C_{20}=-4.6876 \mathrm{E} 6, C_{30}=1.601 \mathrm{E} 5$ \\
Arruda-Boyce model & $C_{10}=3.0994 \mathrm{E} 6, C_{20}=-4.2516 \mathrm{E} 7$ \\
\hline
\end{tabular}

test specimen diameter is equal to the diameter of the double-shear standard cutter.

The frequency scanning test under the double-shear is shown in Figure 5. A $500 \mathrm{~N}$ capacity load cell was selected, the temperature was set to $25^{\circ} \mathrm{C}$, and the scanning range frequency was ranging between 0 and $70 \mathrm{~Hz}$. The logarithmic test measurement method was selected. Finally, measured storage and loss modulus are plotted in dependence on the frequency, as shown in Figures 6 and 7.

2.2.2. Determining the Viscoelastic Constitutive Model Parameters. The generalized Maxwell model can accurately describe the stress relaxation and creep process of rubber materials in a wide frequency and is widely used in the dynamic calculation of rubber materials [18]. It was obtained by connecting multiple Maxwell element models in parallel. In its generalized variant, the modulus and viscosity of each Maxwell element model are different. Therefore, for each element model, every elastic and viscous element have a specific relaxation time while a series of models have a relaxation time spectrum [19]. The generalized Maxwell model is shown in Figure 8.

The generalized Maxwell model includes the expressions for both the energy storage and loss modulus of Prony series:

$$
\begin{aligned}
& E^{\prime}(\omega)=E_{0}\left[1-\sum_{i=1}^{n} g_{i}\right]+E_{0} \sum_{i=1}^{n}\left(\frac{g_{i} \omega^{2} \tau_{i}^{2}}{1+\omega^{2} \tau_{i}^{2}}\right), \\
& E^{\prime \prime}(\omega)=\sum_{i=1}^{n} E_{i} \frac{\omega \tau_{i}}{1+\omega^{2} \tau_{i}^{2}}=E_{0} \sum_{i=1}^{n}\left(\frac{g_{i} \omega \tau_{i}}{1+\omega^{2} \tau_{i}^{2}}\right) .
\end{aligned}
$$

In equation $(8),\left(E_{0}\right)$ is the instantaneous modulus; $g_{i}$ is the ratio between the spring elastic modulus and the total elastic modulus in ith Maxwell model; and $\tau_{\iota}$ is the relaxation time of the $i$ th Maxwell model.

The Prony series coefficient found by fitting the frequency scanning test data under the double-shear through the ANSYS curve fitting module is shown in Table 2. Finally, by establishing the hyperelastic and viscoelastic constitutive models of polyurethane, there is a sufficient basis of material parameters for finding the dynamic simulation using FEM.

\section{Simulation of Shaft Damping Ring Dynamic Characteristics}

The dynamic stiffness reflects the amplitude ratio between the load and the response displacement at a constant frequency. The structural loss factor is an essential parameter for measuring the energy dissipation capacity of the damping ring vibrating under the external force excitation; it

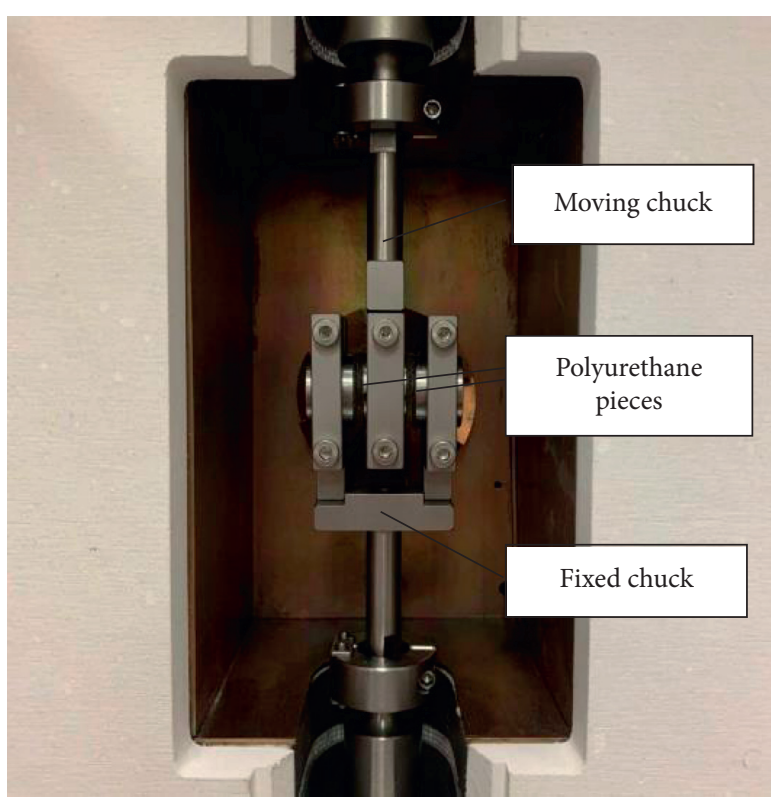

FIGURE 5: Frequency scanning test of double-shear specimen.

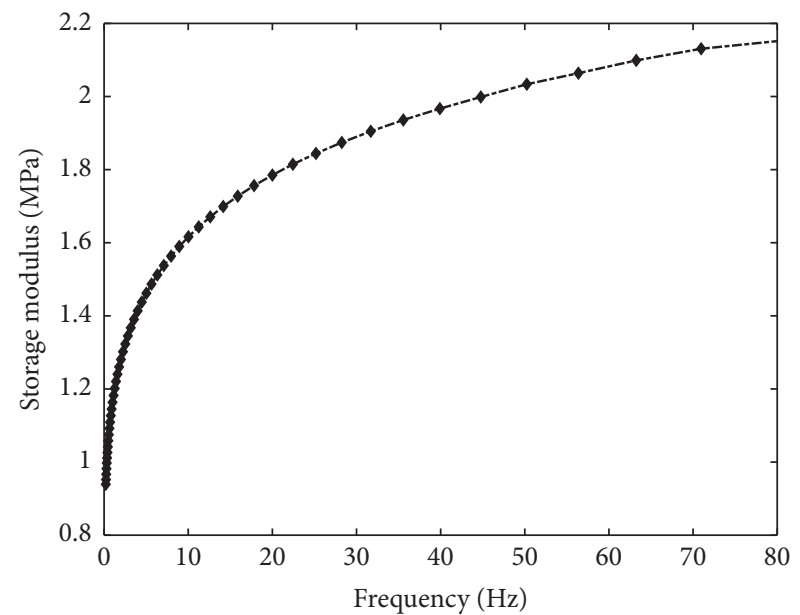

FIGURE 6: Energy storage modulus-frequency test curve of polyurethane pieces.

is used to characterize the ring damping performance. With the increase of the structure loss factor, the vibration reduction effect increases. Regarding the energy dissipation value, it is mainly expressed by the lagging ring area formed by strain lagging stress. As the lagging ring area size increases, the internal friction produced by the material rises; therefore, the damping performance improves. Based on the established polyurethane material constitutive model, the dynamic characteristic simulation of the shaft damping ring is carried out and is verified by the dynamic test. 
TABLe 2: Parameters of the fourth-order generalized Maxwell model.

\begin{tabular}{lccc}
\hline Shear relative modulus & Numerical value & Relaxation time (s) & Numerical value \\
\hline$g_{1}$ & 0.28165 & $\tau_{1}$ & 0.04813 \\
$g_{2}$ & 0.16841 & $\tau_{2}$ & 0.00246 \\
$g_{3}$ & 0.07543 & $\tau_{3}$ & 0.52495 \\
$g_{4}$ & 0.6494 & $\tau_{4}$ & 0.12927 \\
\hline
\end{tabular}

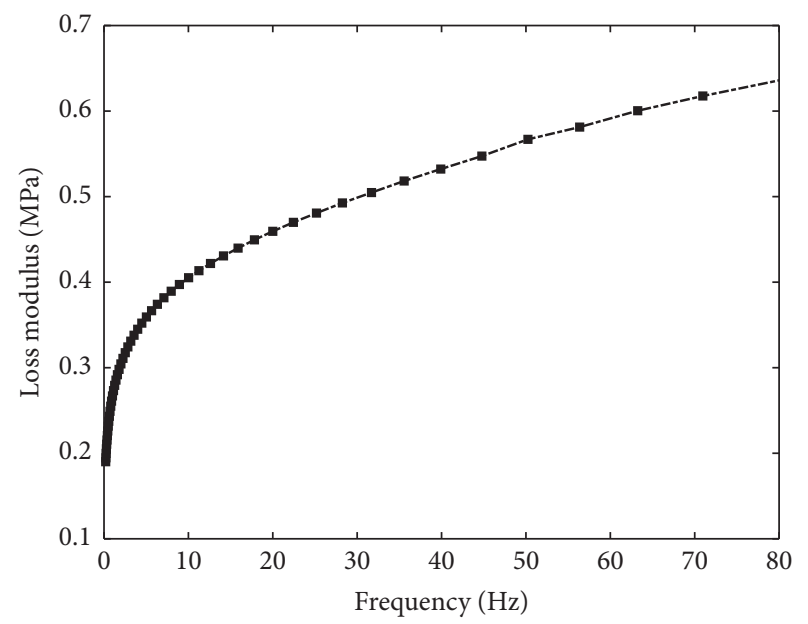

Figure 7: Loss modulus-frequency test curve of polyurethane pieces.

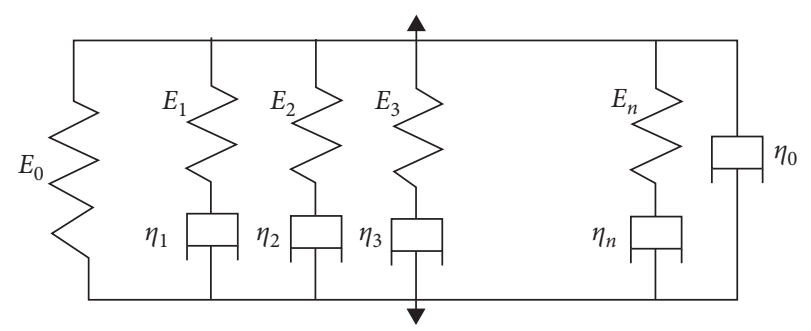

Figure 8: Generalized Maxwell model.

\subsection{Dynamic Characteristic Simulation of the Shaft Damping} Ring. The shaft damping ring studied in this paper is matched with the NSK6205 bearing composed of annular polyurethane rubber and annular metal bushing (for geometric parameters, see Table 3). The inner diameter of the damping ring rubber will be referred to as the inner damping ring diameter, while the outer diameter of the damping ring rubber will be referred to as the outer damping ring diameter.

The annular polyurethane rubber and the metal bushing are joined through the vulcanization process. Thus, the metal bushing displacement can cause the annular polyurethane rubber deformation. The structural and physical diagrams are shown in Figures 9 and 10, respectively. Figure 11 shows the shaft damping ring mounted on the support. The outer rubber ring is connected to the support while the inner rubber ring is connected to the inner metal ring. Finally, the inner metal ring is connected to the bearing, which is fixed on the shaft.

The dynamic characteristics of the shaft damping ring were simulated using the ANSYS transient dynamics

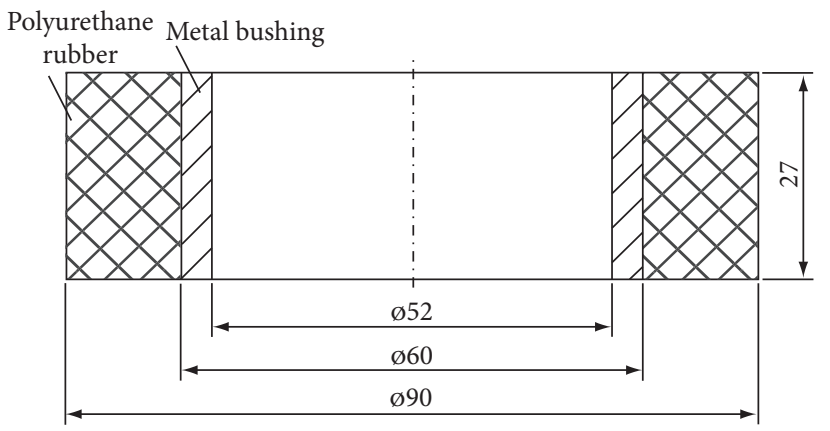

FIgURE 9: Structural drawing of the shaft damping ring.

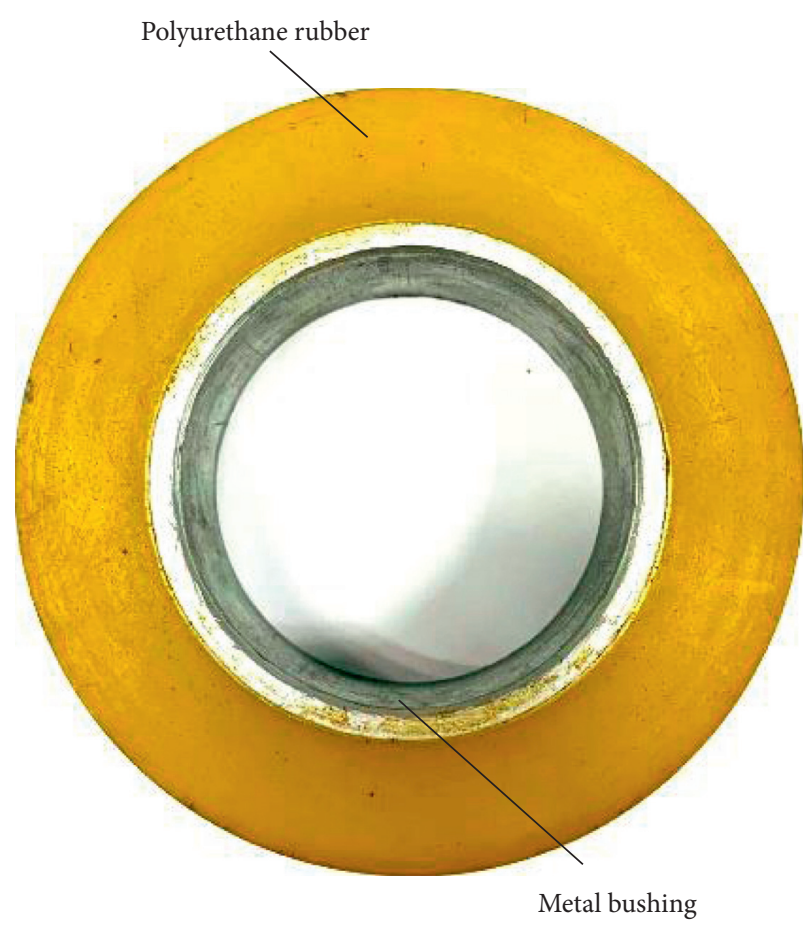

FIGURE 10: Shaft damping ring.

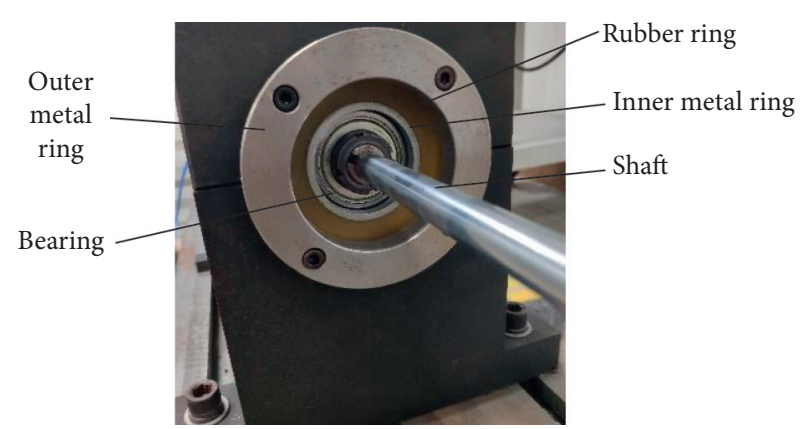

FIGURE 11: Shaft damping ring mounted on the support. 
TABLE 3: Geometric parameters of the shaft damping ring ( $\mathrm{mm}$ ).

\begin{tabular}{llll}
\hline Inner damping ring diameter & Outside damping ring diameter & Outer metal bushing diameter & Inner metal bushing diameter $\quad$ Metal bushing width \\
\hline 60 &
\end{tabular}

60

90

60 27

module. After completing the Geometry modeling using the UG NX software, the ANSYS geometry module was imported. The constitutive model and the polyurethane material parameters obtained in the previous section are defined in the material library. Aiming to improve the model structure, the surface mesh was added to the shaft vibration reduction ring. The mesh size was set to $2 \mathrm{~mm}$ by using volume division.

The shaft system damping ring is installed between the bearing and the bearing seat bored in the tail drive shaft system. The outer rubber ring surface is fixed to the bearing seat bore, while the inner metal bushing ring surface is joined with the outer bearing ring surface. Hence, the outer rubber ring surface is taken as fixed in the dynamic simulation. The frequency of the metal bushing inner ring surface is $4 \mathrm{~Hz}$, and the corresponding amplitude is $0.7 \mathrm{~mm}$. Finally, the resulting dynamic simulation displacement and strain nephogram are obtained through FEM (shown in Figures 12 and 13 , resp.).

As shown in the dynamic simulation of the shaft damping ring (Figure 12), the metal bushing displacement is notable, driving the polyurethane rubber displacement. Since the metal bushing stiffness is much greater compared to the polyurethane rubber stiffness (Figure 13), the strain minimum of the metal bushing hardly changes. However, the polyurethane rubber strain is much greater than the metal bushing strain. To sum up, the displacement movement of the metal bushing extrudes the polyurethane rubber, which causes the polyurethane rubber deformation.

In the postprocessing, the shaft damping ring load and displacement are found, allowing the authors to create the force-displacement hysteresis loop (as shown in Figure 14).

3.2. Dynamic Stiffness Test Verification. To verify the accuracy of the polyurethane rubber material constitutive model, the dynamic characteristics of the shaft damping ring (shore $70 \mathrm{~A})$ were studied experimentally. The experimental equipment included the electrohydraulic servo fatigue machine; the sine wave was used as the excitation loading method. The shaft damping ring loading frequency was $4 \mathrm{~Hz}$, with the displacement excitation amplitude of $0.7 \mathrm{~mm}$. The moving segment of the electrohydraulic servo fatigue machine follows the linear actuator piston, thus achieving the reciprocating linear motion. In the meantime, the shaft damping ring is affected by the cyclic sinusoidal dynamic force along its vertical axis direction (loaded in the jig). The dynamic test of the shaft damping ring is shown in Figure 15.

During the dynamic test, the electrohydraulic servo fatigue machine records the dynamic force and displacement data through the sensor, creating the hysteresis loop of the measured effort-displacement. For more details, see Figure 16.
The dynamic stiffness and loss factor were obtained from the hysteresis loop (shown in Figures 14 and 16). The dynamic stiffness and loss factor of the shaft damping ring is consistent with the test results (shown in Table 4), with an error below $10 \%$, verifying both the constitutive model accuracy and the validity of simulation settings.

\section{Analysis of the Factors Influencing the Dynamic Stiffness and Damping Characteristics}

In the process of simple harmonic excitation, the structural damping ring parameters (inner diameter, outer diameter, and width) impact the dynamic characteristics. The structural parameters of the shaft system damping ring change if the ring is adapted to various types of bearings. At the same time, the driving tail drive frequency and amplitude vary as the rotating speed changes. Different working conditions alter the stress-strain cycle path, hence changing both the dynamic stiffness and loss factor. To study how does each factor affects the shaft damping ring dynamic stiffness and loss factor, the factor analysis was carried out.

\subsection{Analysis of Structural Parameter Influence on Dynamic Stiffness and Damping Characteristics}

4.1.1. Inner Damping Ring Diameter. The dynamic finite element analysis (FEA) of the shaft damping ring was carried out while keeping the harmonic excitation frequency $(32 \mathrm{~Hz})$ and the amplitude $(1.6 \mathrm{~mm})$ constant. The inner damping ring diameters were varied; five sizes were used $-56 \mathrm{~mm}$, $58 \mathrm{~mm}, 60 \mathrm{~mm}, 62 \mathrm{~mm}$, and $64 \mathrm{~mm}$. Dynamic stiffnesses and loss factors were obtained from the simulation results for different damping ring inner diameter sizes, as shown in Figures 17 and 18.

As seen in Figures 17 and 18, the resulting dynamic stiffness of the shaft damping ring is positively correlated with its inner diameter between $56 \mathrm{~mm}$ and $64 \mathrm{~mm}$. Furthermore, the loss factor is negatively correlated with the inner diameter. An increase in the inner damping ring diameter causes an upward trend in the dynamic stiffness and reduces the loss factor. For the inner diameter ranges between $56 \mathrm{~mm}$ and $64 \mathrm{~mm}$, the dynamic stiffness increased by $74.29 \%$, and the loss factor decreased by $0.99 \%$. Finally, the authors conclude that the inner diameter has a much greater effect on the dynamic stiffness than on the loss factor.

4.1.2. Outer Damping Ring Diameter. The vibration frequency is set to $32 \mathrm{~Hz}$, while the amplitude is $1.6 \mathrm{~mm}$; the outer shaft damping ring diameter was varied. The dynamic simulations were carried out for the outer diameter values of $86 \mathrm{~mm}, 88 \mathrm{~mm}, 90 \mathrm{~mm}, 92 \mathrm{~mm}$, and $94 \mathrm{~mm}$. The simulation 


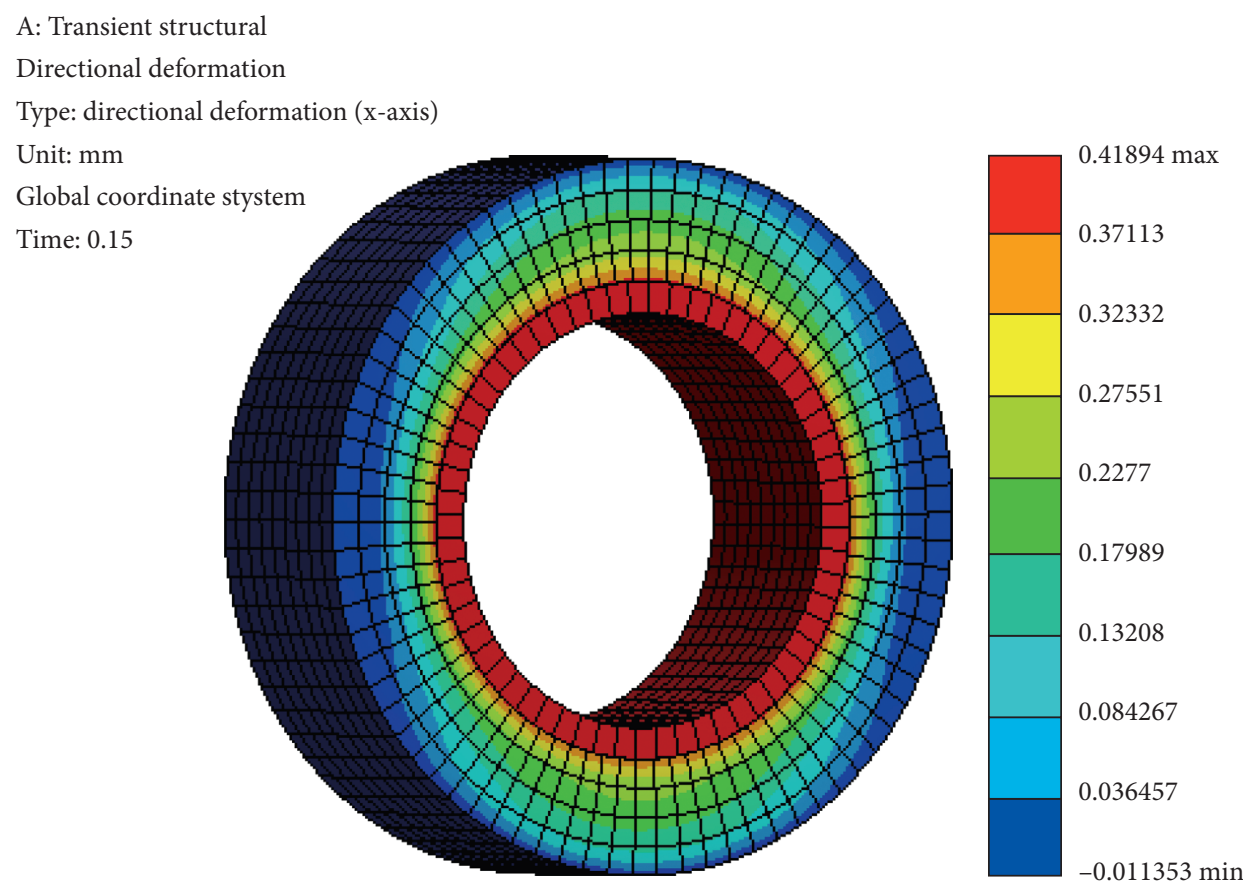

Figure 12: Displacement cloud diagram of shaft damping ring.

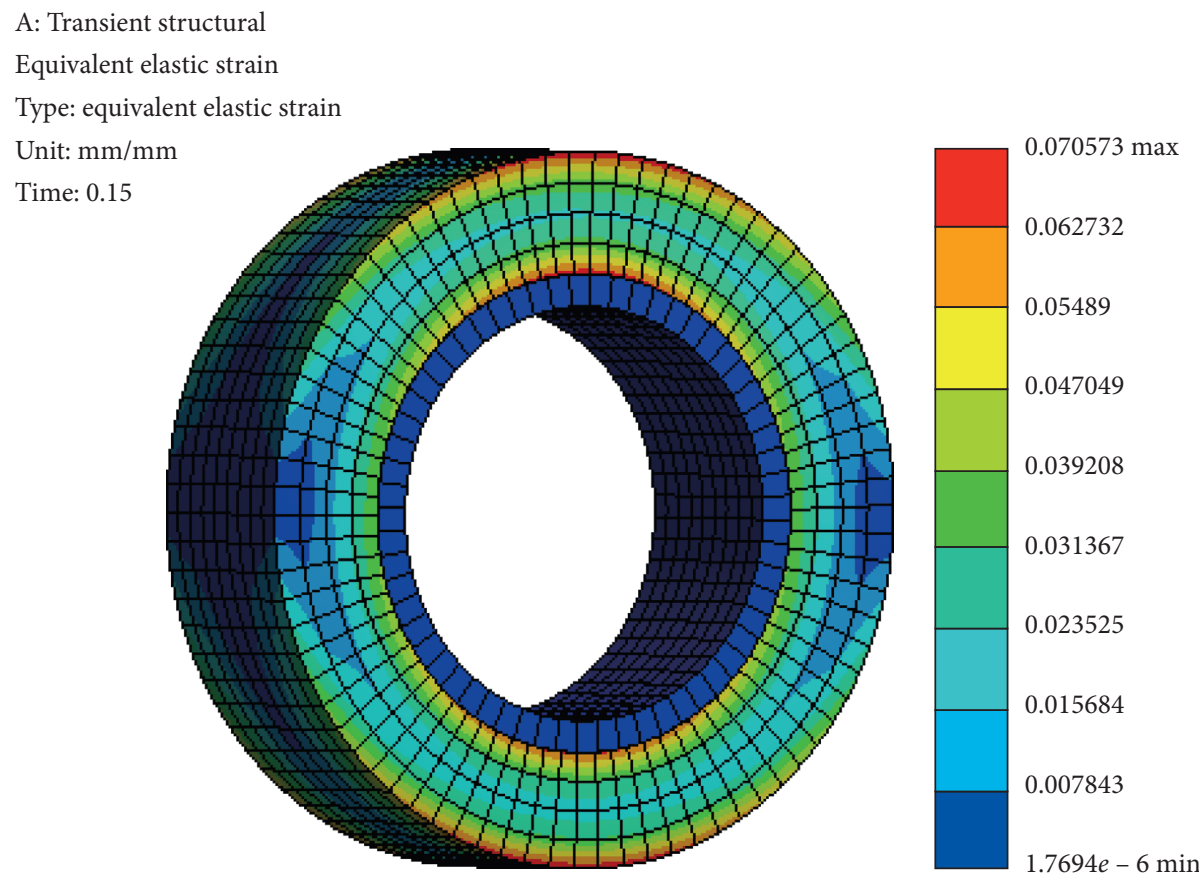

Figure 13: Strain cloud diagram of shaft damping ring.

TABle 4: Dynamic characteristics simulation and test comparison of shaft damping ring.

\begin{tabular}{lcc}
\hline Category & $\begin{array}{c}\text { Dynamic stiffness } \\
(\mathrm{N} / \mathrm{m}) \times 106\end{array}$ & Loss factor \\
\hline $4 \mathrm{~Hz}, 0.7 \mathrm{~mm}$ simulation & 4.6202 & 0.1552 \\
$4 \mathrm{~Hz}, 0.7 \mathrm{~mm}$ test & 4.9298 & 0.1642 \\
Error & $6.7 \%$ & $5.8 \%$ \\
\hline
\end{tabular}

results for the dynamic stiffness and loss factor are shown in Figures 19 and 20.

When the outer damping ring diameter is between $86 \mathrm{~mm}$ and $94 \mathrm{~mm}$, the dynamic stiffness was negatively correlated with the outer diameter, while the correlation with the loss factor was positive (Figures 19 and 20). The dynamic stiffness decreases while increasing the outer diameter. The opposite was observed for the loss factor, which 


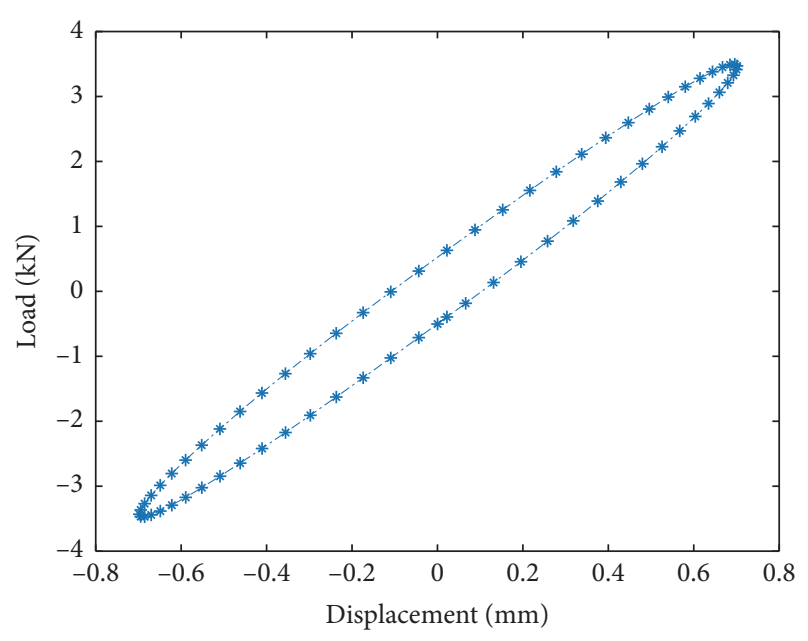

FIgURE 14: The excitation simulation hysteresis loop (for $4 \mathrm{~Hz}$ and $0.7 \mathrm{~mm})$.

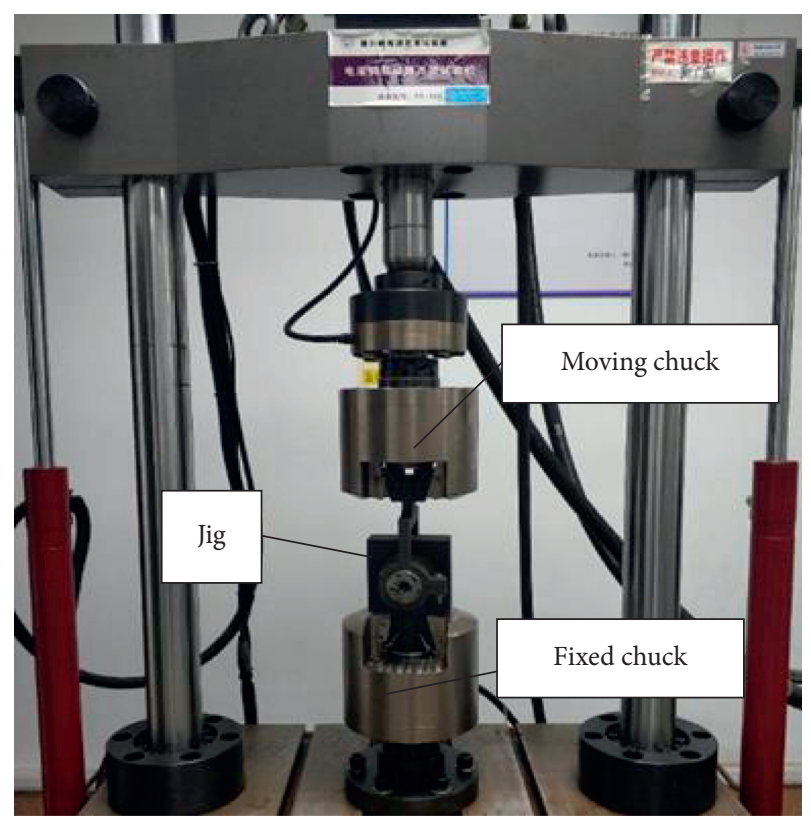

FIgUre 15: Dynamic test of shaft damping ring.

is increased when the outer diameter increased. In the outer diameter range between $86 \mathrm{~mm}$ and $94 \mathrm{~mm}$, the dynamic stiffness is reduced by $34.91 \%$, whereas the loss factor increased by $1.14 \%$. To sum up, variations in the outer diameter affect the dynamic stiffness more significantly compared to the loss factor.

4.1.3. Damping Ring Width. Finally, the influence of the shaft damping ring width on the dynamic stiffness and loss factor was studied at the constant harmonic excitation frequency $(32 \mathrm{~Hz})$ and amplitude $(1.6 \mathrm{~mm})$. A finite element model of shaft vibration reduction ring was created in five widths; the values of $23 \mathrm{~mm}, 25 \mathrm{~mm}, 27 \mathrm{~mm}, 29 \mathrm{~mm}$, and $31 \mathrm{~mm}$ were used while keeping the outer damping ring

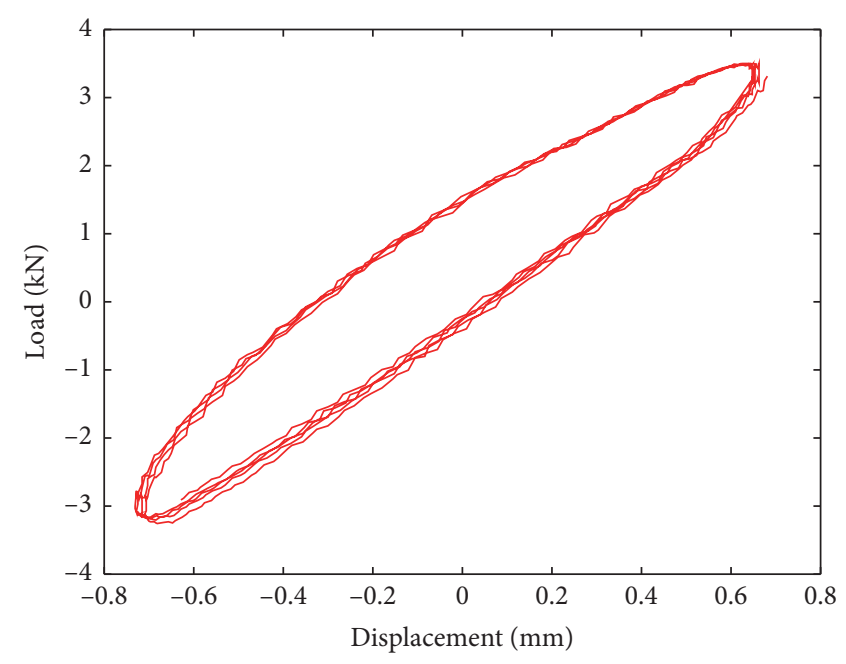

Figure 16: Hysteresis loop ( $4 \mathrm{~Hz}$ and $0.7 \mathrm{~mm}$ excitation test).

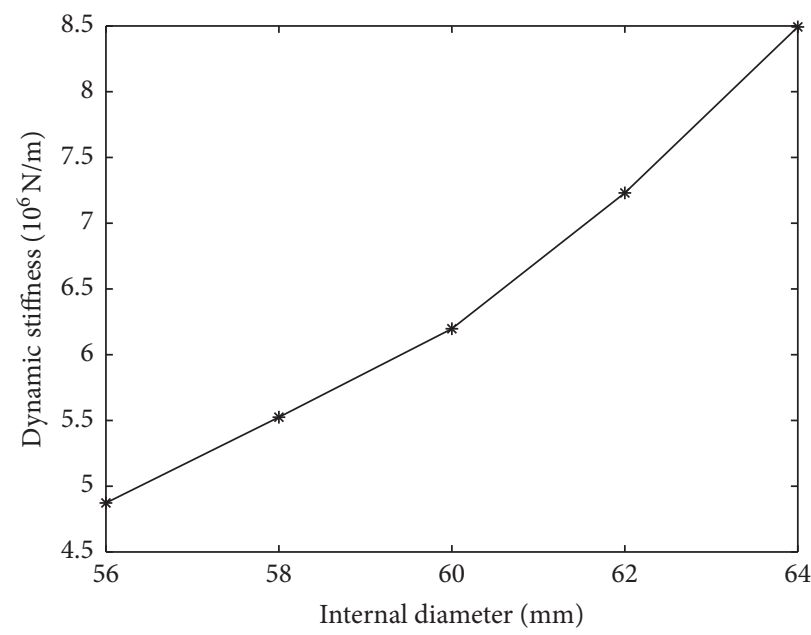

FIGURE 17: Influence of inner damping ring diameter on dynamic stiffness.

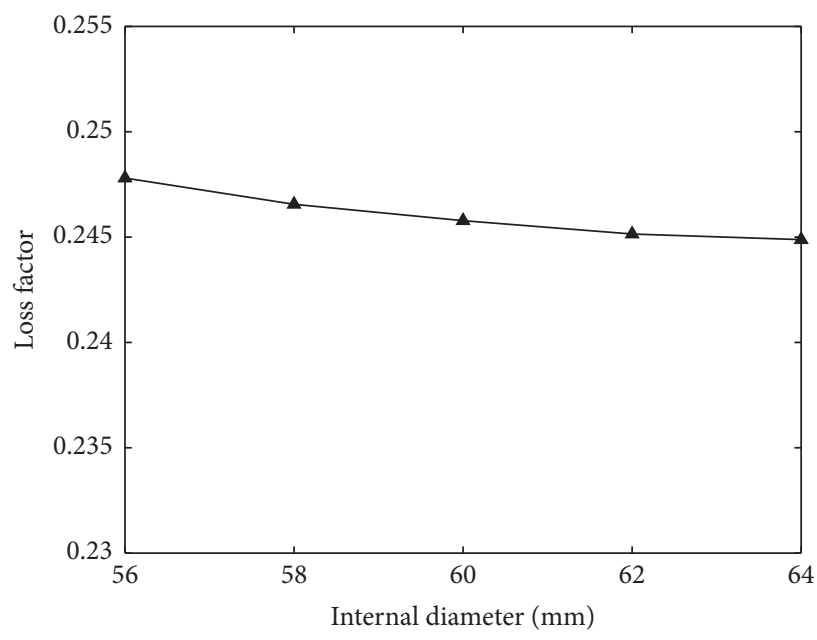

FIGURE 18: Influence of inner damping ring diameter on loss factor. 


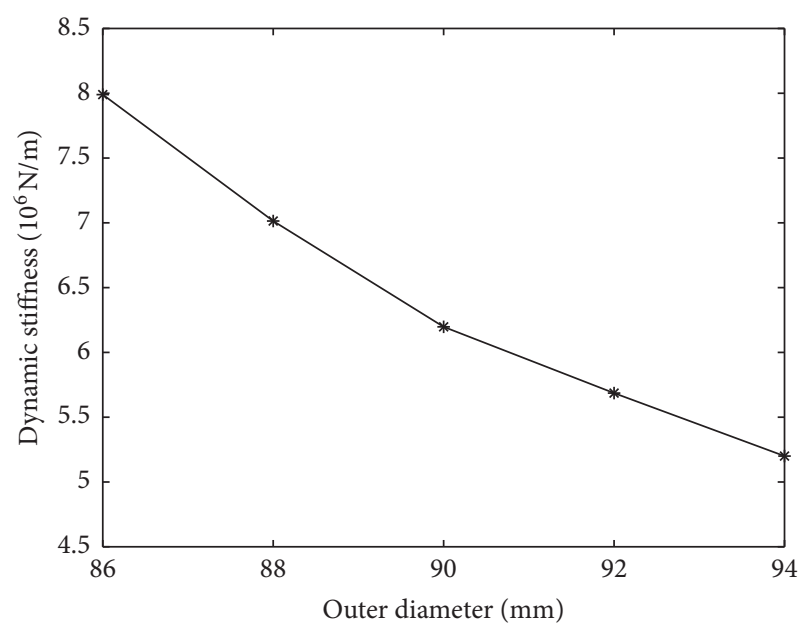

FIgURE 19: Influence of the variations in outer damping ring diameter on the dynamic stiffness.

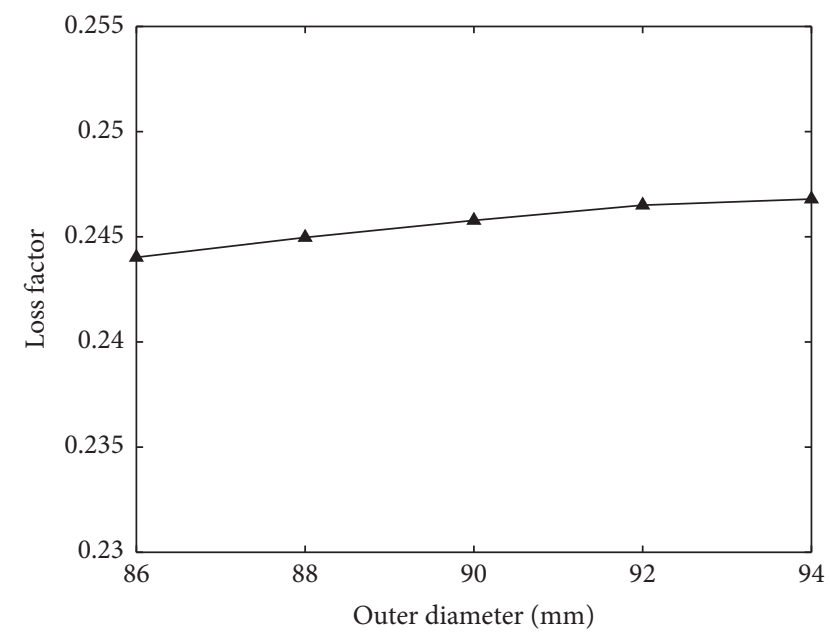

FIGURE 20: Influence of the variations in outer damping ring diameter of on loss factor.

diameter $(90 \mathrm{~mm})$ and the inner damping ring diameter $(60 \mathrm{~mm})$ constant. The resulting dynamic stiffness and loss factors are shown in Figures 21 and 22.

According to Figures 21 and 22, the shaft damping ring width varies between $23 \mathrm{~mm}$ and $31 \mathrm{~mm}$. The dynamic stiffness is positively correlated with the width size, while correlation is negative for the loss factor. In the shaft damping ring width range between $23 \mathrm{~mm}$ and $31 \mathrm{~mm}$, the dynamic stiffness increased by $64.79 \%$, while the loss factor decreased by $1.07 \%$. Similarly to the previous sections, the width was found to have a greater influence on the dynamic stiffness that the loss factor.

\subsection{Analysis of the Influence of Working Condition Parameters on Dynamic Stiffness and Damping Characteristics}

4.2.1. Excitation Frequency. To study the influence of excitation frequency on the shaft damping ring dynamic stiffness and loss factor while keeping the shaft damping ring size constant, the FEA was carried out. Two amplitude and

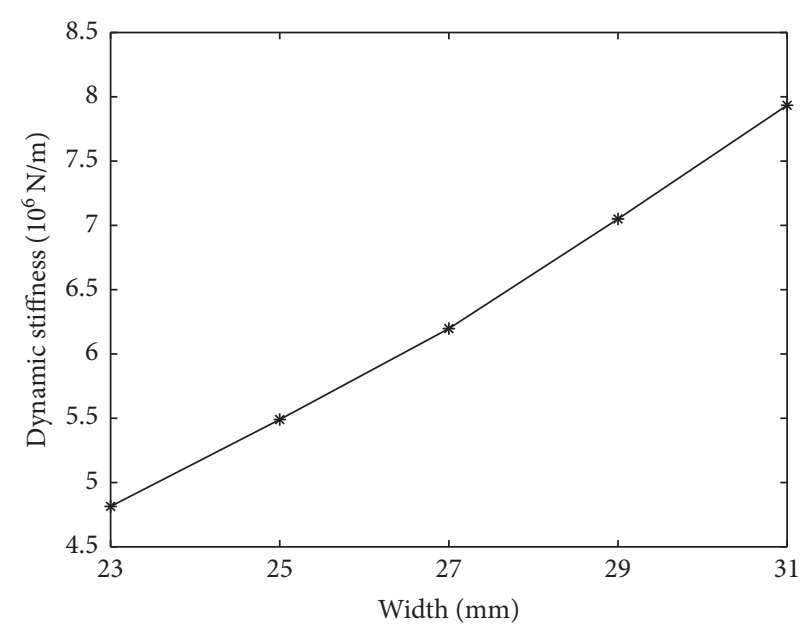

FIGURE 21: The influence of variations in shaft damping ring width on dynamic stiffness.

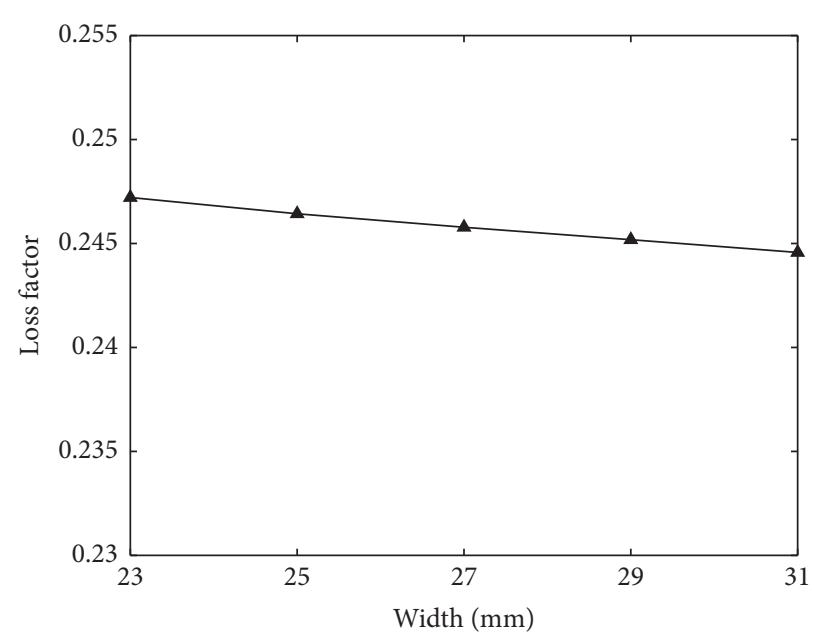

FIGURE 22: The influence of variations in shaft damping ring width on loss factor.

six frequency levels were considered. The amplitudes were $0.6 \mathrm{~mm}$ and $1.2 \mathrm{~mm}$, while the frequencies included $2 \mathrm{~Hz}$, $4 \mathrm{~Hz}, 8 \mathrm{~Hz}, 16 \mathrm{~Hz}, 32 \mathrm{~Hz}$, and $64 \mathrm{~Hz}$, resulting in a total of 12 combinations. The influence of frequency variation on dynamic stiffness for both amplitudes is shown in Figure 23(a), while the corresponding loss factor is shown in Figure 23(b).

Based on the results, the following conclusions were drawn:

(1) For both amplitudes, the dynamic stiffness of the shaft damping ring increases with the simple harmonic excitation frequency. The growth trend is slowing at the low-frequency harmonic excitation and increases rapidly at the high-frequency harmonic excitation. When considering the amplitudes, the dynamic stiffness increases slower at the $1.2 \mathrm{~mm}$ shaft vibration amplitude.

(2) For both amplitudes, the shaft damping ring dynamic stiffness increases with the increase in frequency without significant difference. 


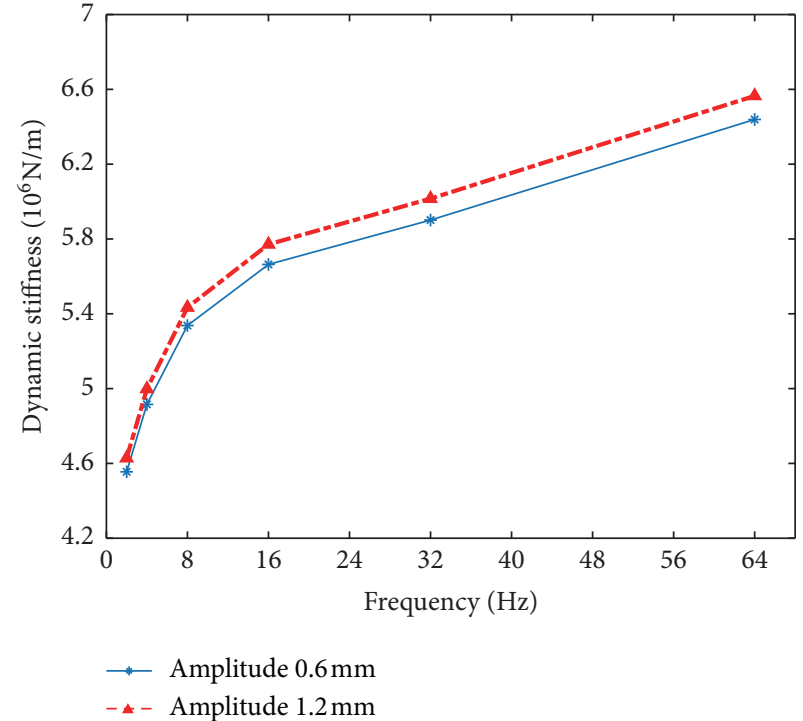

(a)

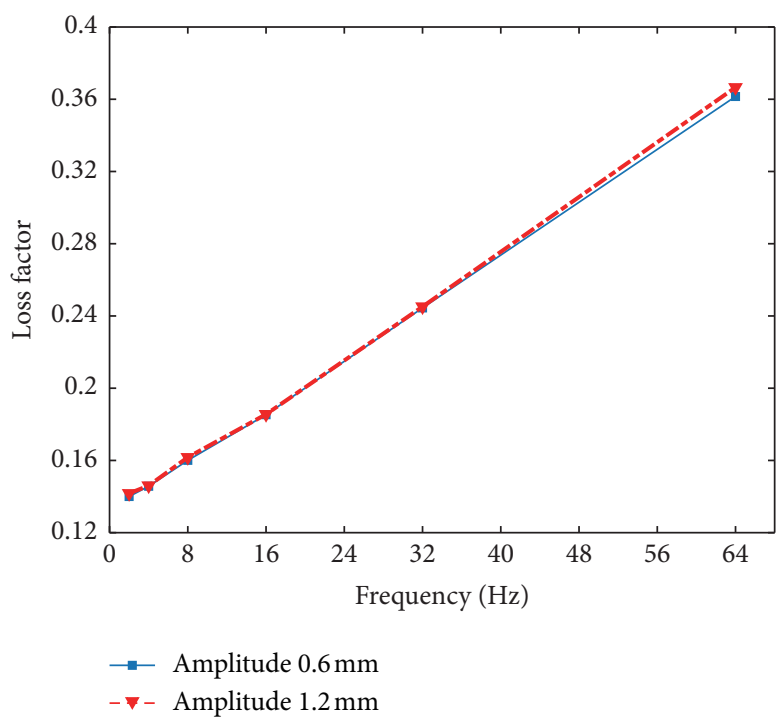

(b)

Figure 23: The influence of frequency on dynamic characteristics of shaft damping ring under different amplitudes. (a) The influence of frequency on dynamic stiffness. (b) The influence of frequency on loss factor.

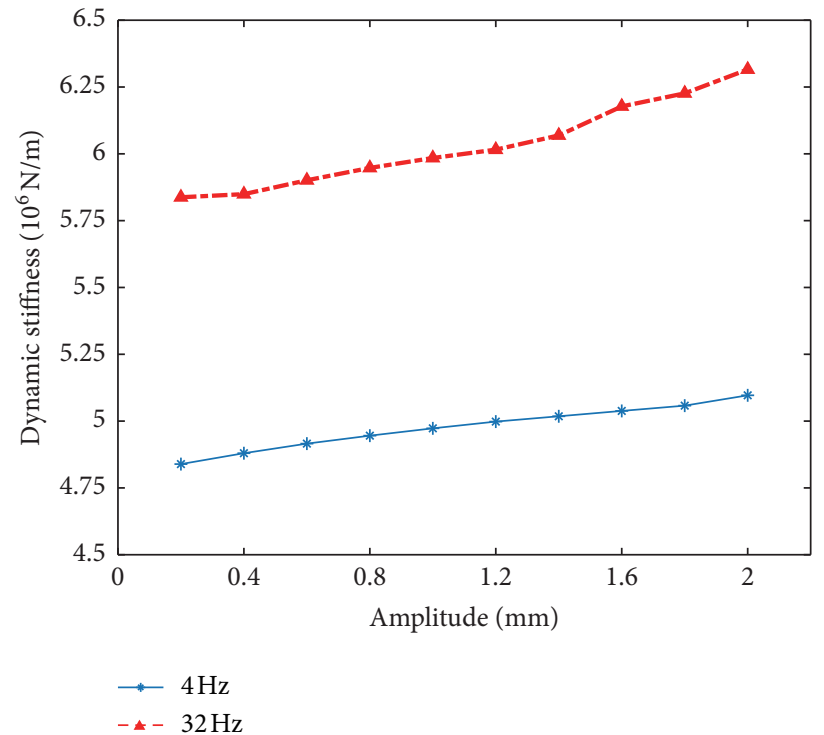

(a)

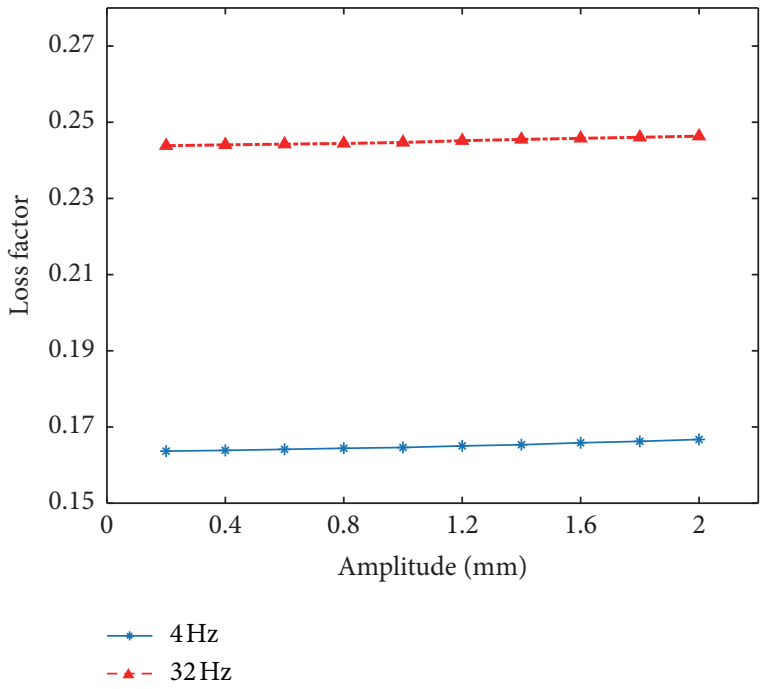

(b)

FIgURE 24: The influence of amplitude at different frequencies on dynamic characteristics of shaft damping ring. (a) The influence of amplitude on dynamic stiffness. (b) The influence of amplitude on loss factor.

(3) For both amplitudes, the loss factor of shaft damping ring increases with the increase in harmonic excitation frequency, following approximately linear growth trend.

(4) The change in harmonic frequency excitation has a greater influence on the loss factor than the dynamic stiffness.

4.2.2. Excitation Amplitude. The finite element simulation of shaft damping ring dynamic stiffness and loss factor was carried out by testing ten amplitude levels: $0.2 \mathrm{~mm}, 0.4 \mathrm{~mm}$, $0.6 \mathrm{~mm}, 0.8 \mathrm{~mm}, 1.0 \mathrm{~mm}, 1.2 \mathrm{~mm}, 1.4 \mathrm{~mm}, 1.6 \mathrm{~mm}, 1.8 \mathrm{~mm}$, and $2.0 \mathrm{~mm}$. The harmonic excitation frequencies were $4 \mathrm{~Hz}$ and $32 \mathrm{~Hz}$. For both frequency values, the influences of amplitude on dynamic stiffness are shown in Figure 24(a), while the effects of amplitude on the loss factor are shown in Figure 24(b).

The following conclusions were drawn from Figure 24:

(1) In the amplitude range between $0.2 \mathrm{~mm}$ and $2.0 \mathrm{~mm}$, the shaft damping ring dynamic stiffness increases with the amplitude. Furthermore, for the same 
amplitude, the dynamic stiffness is higher at a higher frequency $(32 \mathrm{~Hz})$.

(2) For both frequencies, the shaft damping ring dynamic stiffness increases with the increase in the amplitude. Additionally, the shaft damping ring dynamic stiffness increases faster with the increase in the amplitude at the $32 \mathrm{~Hz}$ frequency than at the $4 \mathrm{~Hz}$.

(3) In the amplitude range between $0.2 \mathrm{~mm}$ and $2.0 \mathrm{~mm}$, with the increase in amplitude, the shaft damping ring dynamic stiffness increases faster than the loss factor.

(4) When the simple harmonic mechanism amplitude ranges between $0.2 \mathrm{~mm}$ and $2.0 \mathrm{~mm}$, the loss factor of the shaft damping ring increases slowly with the amplitude. At the same amplitude, the shaft damping ring loss factor under the simple harmonic excitation of $32 \mathrm{~Hz}$ is higher than that under the $4 \mathrm{~Hz}$. With the increase in amplitude, no significant differences were observed for the loss factor increasing trend of the shaft damping ring under the simple harmonic excitation of $32 \mathrm{~Hz}$ and $4 \mathrm{~Hz}$.

(5) The harmonic excitation amplitude affects the damping ring dynamic stiffness more significantly that the loss factor.

\section{Conclusion}

A study on the shaft damping ring dynamic stiffness and damping characteristics was carried out by frequency scanning specimens under the uniaxial tension and doubleshear test. The accurate polyurethane constitutive model was established based on the superelastic and viscoelastic constitutive model. The dynamic simulation was verified by dynamic tests, and influences of both the structural and working damping ring parameters on the dynamic stiffness and damping characteristics were analyzed. The research results have provided a theoretical foundation for the further analysis and design of the shaft damping ring. Based on the results, the authors concluded the following:

(1) Regarding the structural parameters, the influence trends of the damping ring width and inner diameter on the dynamic characteristics are practically the same. With the increase of the inner diameter or the width, the dynamic stiffness increases significantly, while the loss factor slightly decreases. With the increase in outer diameter, the shaft damping ring dynamic stiffness decreases significantly, while the loss factor slightly increases. The influence of inner diameter and width on shaft damping ring dynamic characteristics is greater than that of the outer diameter.

(2) Regarding the working condition parameters, the frequency has a more significant influence on the shaft damping ring dynamic characteristics compared to the amplitude. The dynamic stiffness and loss factor increase as the excitation frequency increases, whereas the dynamic stiffness increasing trend decreases, and the loss factor increasing trend has no obvious differences. The dynamic stiffness increases with the increase in excitation amplitude, following the exponential trend. The loss factor increases slowly as the excitation amplitude increases, while the increasing trend of the loss factor is similar at all frequencies.

\section{Data Availability}

All data included in this study are available upon request to the corresponding author.

\section{Conflicts of Interest}

The authors declare that they have no conflicts of interest.

\section{Acknowledgments}

This work was supported by the National Key Laboratory of Science and Technology on Helicopter Transmission (Nanjing University of Aeronautics and Astronautics) (Grant no. HTL-A-19G09).

\section{References}

[1] Q. Mei, "Dynamics design of helicopter drive shafts," Journal of Mechanical Transmission, vol. 29, no. 5, pp. 19-22, 2005.

[2] L. Zhang, Based on the Integral Elastic Ring Squeeze Film Damper to Suppress the over Critical Vibration of Rotor and Study on Pipe Vibration Control, Beijing University Of Chemical Technology, Beijing, China, 2018.

[3] S. Hamzehlouia and K. Behdinan, "Squeeze film dampers supporting high-speed rotors: fluid inertia effects," Proceedings of the Institution of Mechanical Engineers, Part J: Journal of Engineering Tribology, vol. 234, no. 1, pp. 18-32, 2020.

[4] M. Song, Dynamic Design of Elastic Support/Dry Friction Damper Matching Rotor, Northwestern Polytechnical University, Xi'an, China, 2016.

[5] W. Wu, Study on the Stiffness and Damping Characteristics of Annular Rubber-Silicone Oil Damper, Nanjing University of Aeronautics and Astronautics, Nanjing, China, 2018.

[6] B. Trustee, Helicopter Drive System On-Condition Maintenance capability, Sikorsky Aircraft Division of United Technologies Corporation, Stratford, CT, USA, 1976.

[7] J. M. Hill, "A review of partial solutions of finite elasticity and their applications," International Journal of Non-linear Mechanics, vol. 36, no. 3, pp. 447-463, 2001.

[8] G. Sheng, S. Chang, Y. Li et al., "Test and analysis on the static stiffness of rubber block usedin gear type rubber coupling," Journal of Mechanical Transmission, vol. 37, no. 7, pp. 112116, 2013.

[9] H. S. Lee, J. K. Shin, S. Msolli, and H. S. Kim, "Prediction of the dynamic equivalent stiffness for a rubber bushing using the finite element method and empirical modeling," International Journal of Mechanics and Materials in Design, vol. 15, no. 1, pp. 77-91, 2019.

[10] Y. Liu, J. Cao, Z. Lv, and X. Yang, "Design and simulation research of polyurethane vibration isolator for marine diesel generator set," Chinese Journal of Applied Mechanics, vol. 35, no. 1, pp. 161-235, 2018. 
[11] L. Li, B. Sun, M. He et al., "Analysis of the radial stiffness of rubber bush used in dynamic vibration absorber based on artificial neural network," NeuroQuantology, vol. 16, no. 6, pp. 737-744, 2018.

[12] H. Xie, X. Zhang, and C. Yin, "Comparative analysis of vibration isolation performance of polyurethane and Rubber isolator," Diesel Engine, vol. 37, no. 6, pp. 33-35, 2015.

[13] R. Yang and D. Wang, "Design of polyurethane isolator and simulation analysis of vibration isolation effect," Computer Simulation, vol. 36, no. 9, pp. 75-80, 2019.

[14] D. Huang, B. Wu, and C. Xu, "A new prediction method of dynamic stiffness for the rubber isolator based on finite element analysis," Mechanical Science and Technology for Aerospace Engineering, vol. 32, no. 5, pp. 660-664, 2013.

[15] Y. Liu, J. Cao, Z. Lv et al., "Finite element analysis of polyurethane isolator used in diesel engine set," Chinese Journal of Applied Mechanics, vol. 35, no. 1, pp. 161-165, 2018.

[16] L. Wang, B. Fu, and X. Yang, "Numerical simulation and analysis of carbon-reinforced rubber's Mullins effect," Chinese Journal of Computational Mechanics, vol. 34, no. 3, pp. 372378, 2017.

[17] S. Qian, Y. Lu, X. Yang et al., "Overview of selection and parameter determination for hyperelastic constitutive model of rubber material," Rubber Science and Technology, vol. 16, no. 5, pp. 5-10, 2018.

[18] J. Ming, The Research of Viscoelastic Constitutive Model for Rubber Material and Its Application in Tread Block of Tires, Jilin University, Changchun, China, 2016.

[19] W. Zhang, Powertrain Rubber Mounting Constitutive Relation and Optimization, Tsinghua University, Beijing, China, 2012. 